\title{
ANALISIS GC-MS SENYAWA AKTIF ANTIOKSIDAN FRAKSI ETIL ASETAT DAUN LIBO (Ficus variegata Blume.)
}

\section{Mega Rizky Novitasari, Lizma Febrina, Risna Agustina, Agung Rahmadani, dan Rolan Rusli*}

Fakultas Farmasi Universitas Mulawarman, Samarinda, Kalimantan Timur

*email: rolan@farmasi.unmul.ac.id

\begin{abstract}
ABSTRAK
Daun Libo (Ficus variegata Blume.) memiliki daun yang tidak dimakan oleh hama/serangga, hal ini diduga karena kandungan metabolit sekunder daun libo mengandung senyawa aktif yang potensial salah satunya adalah sebagai antioksidan. Penelitian ini dilakukan untuk mengetahui komponen senyawa antioksidan fraksi etil asetat daun libo dengan metode GC-MS. Interpretasi spektrum massa GC-MS dilakukan dengan menggunakan database WILLEY9THN 08.L. Hasil analisis spektrum GC-MS fraksi etil asetat aktif antioksidan mengandung 2,5-Cyclohexadiene-1,4-dione, 2,6bis(1,1-dimethylethyl (0,65\%), 1-Octadecene (1,29\%), 2-Hexadecen-1-ol, 3,7,11,15tetramethyl- (1,54\%), 7,9-Di-tert-butyl-1-oxaspiro(4,5)deca-6,9-diene-2,8-dione (1,52\%), 1-Nonadecene (3,39\%), 1-Docosene (3,39\%), Nonadecyltrifluoroacetate (2,12\%), 1,2-Benzenedicarboxylic acid,(2-ethylhexyl) ester (45,53\%), 1-Docosene (2,71\%), Pyrene, hexadecahydro (4,56\%), Urs-12-en-3-ol, acetate,(3.beta.) (1,97\%), 12-Oleanen-3-yl acetate, (3.alpha.)- (5,19\%), Urs-12-en-3-ol, acetate,(3.beta.) (1,53 $\%)$ Taraxasterol-acetate (0,30\%), 1-(Dimethylamino)-5-\{[4'-(5"-(4"'-iodophenyl ethynyl|)-1"-naphthylethynyl]-1(8,46\%), dan 7,8,17,18-Tetrahydro-35-methoxy1,3,21,23-tetramethyl-16H,31H-5,9,15,19-dime (10,04\%).
\end{abstract}

Kata kunci: Libo (Ficusvariegata Blume.), fraksi etil asetat, GC-MS, antioksidan

\section{PENDAHULUAN}

Tumbuhan Libo (Ficus varieagata Blume) memiliki potensi yang cukup baik untuk dikembangkan, hal ini dikarenakan ekstrak libo telah dilaporkan memiliki beberapa aktivitas biologi, seperti yang telah dilaporkan oleh Rijai (2013). Beberapa aktivitas biologi dari ekstrak libo tersebut antara lain aktivitas antioksidan, antibakteri, dan sitotoksik secara invitro, serta larvasida terhadap A. Aegypty (Rijai, 2013).
Senada dengan hal tersebut Rusli, dkk (2015) telah melaporkan pula bahwa isolat fraksi $n$-heksana tanaman libo memiliki aktivitas sebagai antioksidan dan antibakteri. Demikian pula dengan isolat fraksi etilasetat tanaman libo tersebut juga memiliki aktivitas sebagai antioksidan dan antibakteri, seperti yang telah dilaporkan oleh Mega, dkk, (2015). Melihat potensi tanaman libo yang sangat potensial tersebut maka perlu dilakukan penentuan struktur isolat fraksi etilaetat tanaman libo yang memiliki aktivitas sebagai antioksidan dengan menggunakan GC-MS. 


\section{METODE PENELITIAN}

\section{Isolasi Senyawa Fraksi Etil Asetat dan Uji Aktivitas Antioksidan}

Prosedur isolasi dan uji aktivitas antioksidan ini seperti yang telah dilaporkan oleh Mega dkk, (2015). Ekstrak daun Libo hasil maserasi menggunakan pelarut methanol selanjutnya difraksinasi dengan pelarut n-heksana kemudian dilanjutkan dengan pelarut etilasetat. Fraksi etilasetat disolasi dengan dua tahap yaitu dengan metode Kromatografi Cair Vakum (KCV) dan Kromatografi Kolom Konvensional (KK). Isolasi fraksi etilasetat pada tahap KCV dilakukan dengan menggunakan eluen $n$-heksana : etilasetat yang dilanjutkan dengan eluen kloroform : methanol. Tahapan berikutnya adalah dilakukan isolasi lanjutan menggunakan metode KK dengan eluen $n$-heksana:etil asetat. Fasa diam yang digunakan pada KCV dan KK adalah silica gel GF 60. Isolat yang dihasilkan kemudian diuji aktivitas antioksidannya menggunakan KLT bioautografi, untuk diketahui isolat fraksi etilasetat yang memiliki aktivitas antioksidan.

\section{Analisis Senyawa Menggunakan GC- MS \\ Fraksi aktif antioksidan tanaman libo dianalisis menggunakan Gas Chromatograpy-Mass Spectroscopy (GC-MS) Shimadzu QP 5000. Sampel sebanyak $1 \mu \mathrm{L}$ diinjeksikan ke GC-MS yang dioperasikan menggunakan kolom kaca panjang $25 \mathrm{~m}$, diameter $0,25 \mathrm{~mm}$ dan ketebalan $0,25 \mu \mathrm{m}$ dengan fasa diam CP-Sil 5CB dengan temperatur oven diprogram antara 70-270 ${ }^{\circ} \mathrm{C}$ dengan laju kenaikan temperatur $10{ }^{\circ} \mathrm{C} /$ menit, gas pembawa Helium bertekanan $12 \mathrm{kPa}$, total laju $30 \mathrm{~mL} / \mathrm{menit}$ dan split ratio sebesar 1:50.}

\section{HASIL DAN PEMBAHASAN}

Isolat fraksi etilasetat daun libo yang memiliki aktivitas antioksidan adalah fraksi FEA1 (Mega, dkk., 2015). Isolat ini diidentifikasi komponen senyawanya menggunakan GC-MS yang hasilnya seperti terlihat pada Gambar 1.

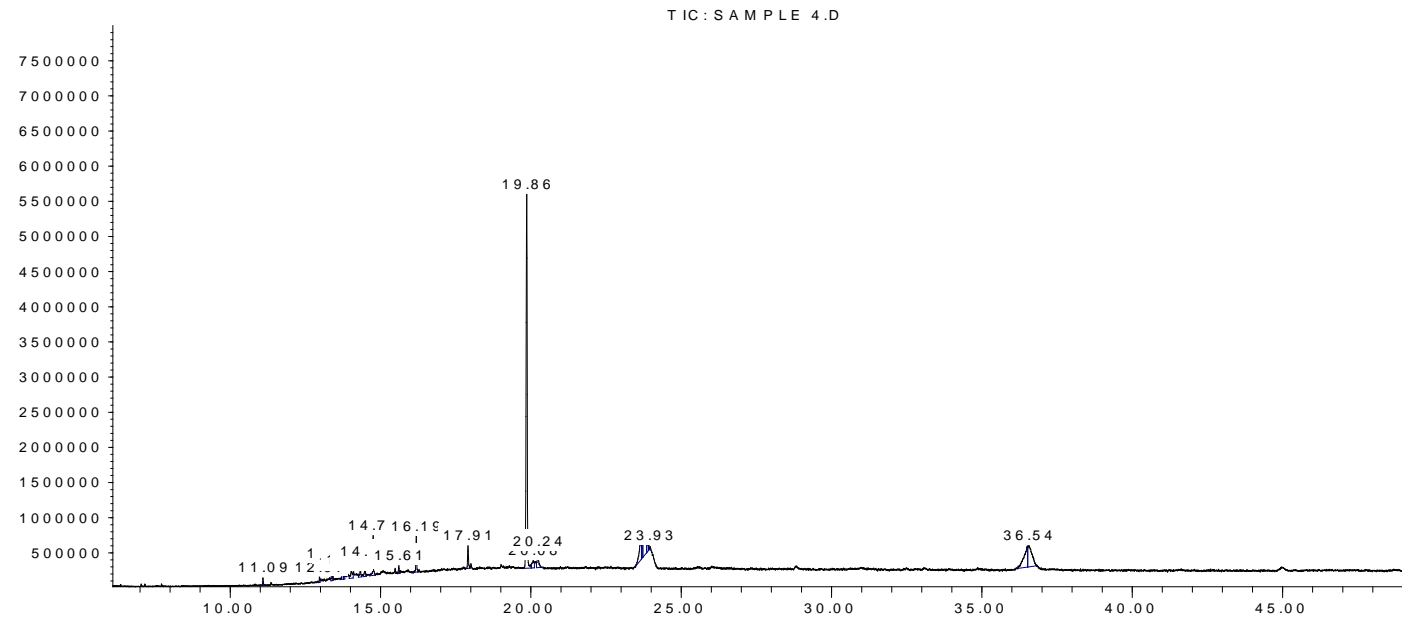

Gambar 1. Kromatogram GC-MS Fraksi Aktif Antioksidan Etil Asetat Daun Libo 
Identifikasi komponen senyawa isolat fraksi FEA1 dilakukan dengan membandingkan pola fragmentasi spektrum massa dengan pola fragmentasi senyawa referensi. Data hasil analisis komponen senyawa isolat FEA1 dengan menggunakan bank data WILLEY9THN 08.L dapat dilihat pada Tabel 1.

Berdasarkan hasil analisis GCMS komponen senyawa isolat fraksi etilasetat daun libo pada Tabel 1, diperoleh bahwa komponen mayor (utama) dari fraksi tersebut adalah senyawa 1,2-Benzenedicarboxylic acid,(2-ethylhexyl) ester dengan kandungan sebesar $45,53 \%$ dan 12Oleanen-3-yl acetate, (3.alpha) dengan kandungan sebesar $4,56 \%$. Struktur kimia kedua komponen mayor isolat fraksi etilasetat ini dapat dilihat pada Gambar 2. Kedua komponen mayor isolat fraksi etilasetat daun libo ini memiliki aktivitas antioksidan dan beberapa aktivitas lainnya. Hal ini berkesesuaian dengan beberapa hasil penelitian yang telah dilaporkan oleh beberapa peneliti seperti yang dirangkum dalam Tabel 2.

Tabel 1. Hasil analisis GC-MS komponen kimia fraksi aktif FEA1

\begin{tabular}{|c|c|c|c|c|}
\hline Peak & $\begin{array}{l}\text { Waktu } \\
\text { Retensi }\end{array}$ & $\begin{array}{c}\% \\
\text { Area }\end{array}$ & Komponen Kimia & Qual \\
\hline 1 & 11,10 & 0,65 & $\begin{array}{c}\text { 2,5-Cyclohexadiene-1,4-dione, 2,6-bis(1,1- } \\
\text { dimethylethyl)- }\end{array}$ & 97 \\
\hline 2 & 13,38 & 1,29 & 1-Octadecene & 98 \\
\hline 3 & 13,73 & 1,54 & $\begin{array}{c}\text { 2-Hexadecen-1-ol, 3,7,11,15-tetramethyl-, } \\
{\left[R-\left[R^{*}, R^{*}-(E)\right]\right]-}\end{array}$ & 64 \\
\hline 4 & 14,48 & 1,52 & $\begin{array}{c}\text { 7,9-Di-tert-butyl-1-oxaspiro(4,5)deca-6,9- } \\
\text { diene-2,8-dione }\end{array}$ & 78 \\
\hline 5 & 14,75 & 3,39 & 1-Nonadecene & 94 \\
\hline 6 & 16,19 & 2,99 & 1-Docosene & 99 \\
\hline 7 & 17,91 & 2,12 & Nonadecyl trifluoroacetate & 89 \\
\hline 8 & 19,86 & 45,53 & $\begin{array}{c}\text { 1,2-Benzenedicarboxylic acid,(2-ethylhexyl) } \\
\text { ester }\end{array}$ & 91 \\
\hline 9 & 20,24 & 2,71 & 1-Docosene & 94 \\
\hline 10 & 23,64 & 4,56 & Pyrene, hexadecahydro- & 66 \\
\hline 11 & 23,69 & 1,97 & Urs-12-en-3-ol, acetate,(3.beta.) & 90 \\
\hline 12 & 23,79 & 5,19 & 12-Oleanen-3-yl acetate, (3.alpha.)- & 95 \\
\hline 13 & 23,86 & 1,53 & Urs-12-en-3-ol, acetate,(3.beta.) & 90 \\
\hline 14 & 23,93 & 0,30 & taraxasterol-acetate & 78 \\
\hline
\end{tabular}

Tabel 2. Aktivitas Biologi dari Senyawa Mayor yang Teridentifikasi Melalui GS-MS

\begin{tabular}{cl}
\hline Senyawa & \multicolumn{1}{c}{ Aktivitas Biologi } \\
\hline 1,2-Benzenedicarboxylic acid,(2- & Antijamur, anti tumor, anti diabetes, anti \\
ethylhexyl) ester & kanker, antioksidan, anti inflamasi, potensi \\
& antimikrobial (Syeda dkk, 2011; Balachandran \\
& dkk, 2012; dan Bagayathi dkk, 2012). \\
12-Oleanen-3-yl acetate, (3.alpha.)- & Antioksidan dan sitotoksik (Fabiyi dkk, 2015) \\
\hline
\end{tabular}




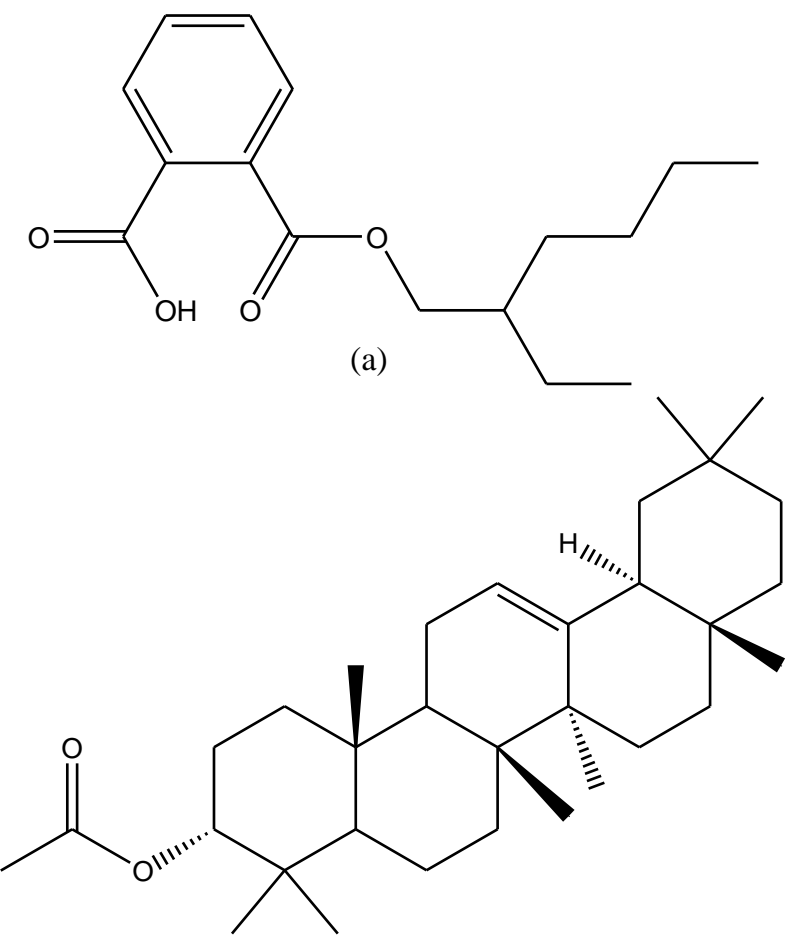

(b)

Gambar 2. Struktur Kimia Komponen Mayor Hasil Identifikasi GC-MS Isolat Fraksi Etilasetat Daun Libo (a) 1,2-Benzenedicarboxylic acid,(2-ethylhexyl) ester dan (b) 12-Oleanen-3-yl acetate, (3.alpha.)-.

Komponen mayor isolat fraksi etilasetat daun libo merupakan senyawa golongan steroid. Senyawa golongan steroid berbentuk siklik atau asiklik dan sering memiliki gugus alkohol, aldehida, atau asam karboksilat (Gambar 2). Steroid memiliki bioaktivitas yang penting, misalnya dalam pembentukan struktur membran, pembentukan hormon dan vitamin $\mathrm{D}$, sebagai penolak dan penarik serangga dan sebagai antimikroba.

\section{KESIMPULAN}

Dua komponen mayor senyawa aktif antioksidan pada isolat fraksi etilasetat daun libo adalah 1,2Benzenedicarboxylic acid,(2-ethylhexyl) ester dan 12-Oleanen-3-yl acetate, (3.alpha.).

\section{DAFTAR PUSTAKA}

1. Bagavathi, P.E., dan Ramasamy, N., 2012. GC-MS analysis of phytocomponents in the ethanol extract of Polygonum chinense L. Pharmacognosy Research. No 14 Hal 11-14

2. Balachandran, C., Lakshmi, R.S., Duraipandiyan, V., dan Ignacimuthu S., 2012. Antimicrobial activity of Streptomyces sp. (ERI-CPDA-1) isolated from oil contaminated soil from Chennai, India. Bioresource Technology. Hal 129.

3. Rolan Rusli, Myra Puspha Hardina, Fairul Muflihah, Agung Rahmadani. 2015, Profil Kromatografi Senyawa Aktif Antioksidan dan Antibakteri Fraksi $n$-Heksana Daun Libo (Ficus variegata Blume). J. Trop. Pharm. Chem. 3. (2). 124-130. 
4. Mega Rizky Novitasari, Risna Agustina, Agung Rahmadani, Rolan Rusli, 2015. Profil Kromatografi Senyawa Aktif Antioksidan dan Antibakteri Fraksi Etil Asetat Daun Libo (Ficus variegata Blume.). Jurnal Sains dan Kesehatan. 1. (3). 131-137.

5. Rijai, Laode. 2013. Potensi Tumbuhan Libo (Ficus variegata Blume) Sebagai Sumber Bahan
Farmasi Potensial. J. Trop. Pharm. Chem. 2 (3): 166-179.

6. Syeda, F.A, Habib-Ur- Rehman, Choudahry, M.I., and Atta-UrRahman. 2011. Gas Chromatography-Mass Spectrometry (GC-MS) analysis of petroleum ether extract (oil) and bioassays of crude extract of Iris germanica. International Journal of Genetics and Molecular Biology. Vol 3 No 7, Hal 95-100. 